\title{
Os saberes atitudinais e a metodologia callejera na educação física escolar
}

\author{
Atitudinals knowledge and callejera methodology in school physical education \\ Conocimientos actitudinales y metodología callejera en educación física escolar \\ FABio de MORAES ${ }^{1}$; YARA APARECida COUTO ${ }^{2}$ \\ UNIVERSIDAde FEDERAL DE SÃo CARLOS, UFSCAR, SÃo CARLOS-SP, BRASIL \\ RESUMO
}

Temos nesse artigo a apresentação dos saberes atitudinais que emergiram a partir das intervenções em aulas de Educação Física com a aplicação de uma Unidade Didática em Esportes de Invasão através da Metodologia Callejera. A Metodologia Callejera é derivada do Fútbol Callejero, tendo sua dinâmica desenvolvida a partir da realização de um jogo composto por times mistos realizado em três Tempos, no $1^{\circ}$ Tempo são estabelecidas as regras, no $2^{\circ}$ Tempo joga-se balizado pelas regras criadas anteriormente e no $3^{\circ}$ Tempo temos a contagem dos pontos para o placar final. A pesquisa ação foi realizada com alunos/as do $5^{\circ}$ ano do Ensino Fundamental de uma escola pública da rede estadual na cidade de São Carlos, São Paulo. As observações foram registradas em um diário de campo e retomadas para uma análise qualitativa, na qual emergiram duas categorias: "Mas ele ééé boooom!" e "As meninas ficam fazendo unha!".

Palavras-chave: Metodologia Callejera. Saberes Atitudinais. Educação Física Escolar.

\begin{abstract}
In this article we have the presentation of the atitudinals knowledge that emerged from the interventions in Physical Education with the application of a Didactic Unit in Invasion Sports through the Callejera Methodology. The Callejera Methodology is derived from Fútbol Callejero, having its dynamics developed from the realization of a game composed of mixed teams held in three Times, in the 1st Half the rules are established, in the 2nd Half it is played out based on the rules previously created and in 3rd time we have the points count for the final score. The action research was carried out with students from the 5th year of elementary school at a public school in the state network in the city of São Carlos, São Paulo. The observations were recorded in a field diary and resumed for a qualitative analysis, in which two categories emerged: "But he is goood!" and "The girls are doing nails!".
\end{abstract}

Keywords: Callejera Metodology. Atitudinals Knowledge. School Physical Education.

\section{RESUMEN}

En este artículo tenemos la presentación de los conocimientos actitudinales surgidos de las intervenciones en las clases de Educación Física con la aplicación de una Unidad Didáctica en Deportes de Invasión a través de la Metodología Callejera. La Metodología Callejera se deriva del Fútbol Callejero, teniendo su dinámica desarrollada a partir de la realización de un juego compuesto por equipos mixtos celebrado en tres Tiempos, en el ler Tiempo se establecen las reglas, en el 2do Tiempo se juega en base a las reglas previamente creadas $3^{\mathrm{a}}$ vez tenemos el recuento de puntos para la puntuación final. La investigación-acción se llevó a cabo con estudiantes del quinto año de la escuela primaria de una escuela pública de la red estatal de la ciudad de São Carlos, São Paulo. Las observaciones se registraron en un diario de campo y se reanudaron para un análisis cualitativo, en el que surgieron dos categorías: “¡Pero él es bueeeeno!” y “iLas chicas están haciendo uñas!”.

Palabras clave: Metodología Callejera. Conocimientos Actitudinales. Educación Física Escolar.

\footnotetext{
${ }^{1}$ Mestre em Educação Física (ProEF/UFSCar). E-mail: fademora34@gmail.com. ORCID: http://orcid.org/00000001-9899-9286.

${ }^{2}$ Professora Associada do Departamento de Educação Física e Motricidade Humana da UFSCar e do Mestrado Profissional em Educação Física em Rede Nacional (ProEF/UFSCar). E-mail: yaracouto@ufscar.br. ORCID: http://orcid.org/0000-0003-1851-4889.
} 


\section{INTRODUÇÃO}

O presente artigo teve origem na Dissertação de Mestrado "Educação Física Escolar e a contribuição da Metodologia Callejera nos Conhecimentos Atitudinais", apresentada no Programa de Mestrado Profissional em Educação Física em Rede Nacional (ProEF/UFSCar).

O programa tem como proposta capacitar professores da área de Educação Física da rede pública de ensino para a docência na Educação Básica, com o intuito de contribuir para a melhoria da qualidade do ensino no País; e nesse sentido a construção do Trabalho de Conclusão é uma pesquisa de intervenção no contexto escolar no qual o professor/a atua. Tendo em vista o objetivo do programa a pesquisa aqui delineada teve como foco observar os conhecimentos atitudinais que emergiram das intervenções em aulas de Educação Física com a aplicação de uma Unidade Didática em Esportes de Invasão $^{3}$ através da Metodologia Callejera.

A Metodologia Callejera (CASTRO, 2018) é derivada do Fútbol Callejero ${ }^{4}$, um jogo de times compostos por meninos e meninas organizado em três Tempos:

[...] em uma conversa inicial entre todos/as participantes ( $1^{\circ}$ Tempo) ocorre o estabelecimento das regras do jogo que será realizado, daí, logo em sequência, temos o jogo propriamente dito ( $2^{\circ}$ Tempo) que acontecerá após terem sido acordadas as regras e, finalmente, temos as discussões que acontecerão no $3^{\circ}$ Tempo, também chamado de Mediação, no qual ocorre a contagem do placar para além do resultado do jogo. Nesse momento todos/as envolvidos se reúnem e verificam a pontuação final considerando também os quesitos Respeito, Cooperação/Companheirismo e Solidariedade. A verificação desses Pilares é auxiliada por um Mediador/Mediadora e são disparadas pelas ações que ocorreram no jogo (MORAES, 2020, p. 11).

O Fútbol Callejero é uma prática social originada na rua e que estimula a inclusão, cooperação, autoestima e o despertar político (ROSSINI e colaboradores, 2012).

Para proporcionar as vivências do Fútbol Callejero nas aulas de Educação Física algumas adaptações são necessárias, visto que é uma prática desenvolvida em tempos e espaços diferentes dos impostos pela rotina escolar.

A proposição de vivências na perspectiva da Metodologia Callejera e mesmo do Fútbol Callejero nas Escolas é recente e a produção científica ainda é pouca, no entanto, serviram para fundamentar esse estudo.

Em 2009, Leonel Sánchez e Juan Salermo propuseram o Fútbol Callejero nos jogos Interescolares na cidade de Chos Malal, Argentina, relatando que algumas escolas começaram a jogar a partir desse evento. Eles também dão indícios de terem vivenciado nas escolas jogos populares que aplicavam a "Metodologia Callejera" (SÁNCHEZ; SALERMO, 2012); Castro (2018), em sua Dissertação de Mestrado, apresenta o termo "Metodologia Callejera"; Gonçalves Junior e colaboradores (2018) utilizam as falas de

\footnotetext{
3 “'Invasão ou territorial: conjunto de modalidades que se caracterizam por comparar a capacidade de uma equipe ao introduzir ou levar uma bola (ou outro objeto) a uma meta ou setor da quadra/campo defendida pelos adversários (gol, cesta, touchdown etc), protegendo, simultaneamente, o próprio alvo, meta ou setor do campo (basquetebol, frisbee, futebol, futsal, futebol americano, handebol, hóquei sobre grama, polo aquático, rúgbi etc.)" (SÃO PAULO, 2019, p. 260).

${ }^{4}$ Não apresentaremos aqui o histórico do Fútbol Callejero tendo em vista o espaço necessário para trazer essas informações neste artigo. Para saber mais sobre todo o histórico e metodologia indicamos a leitura do artigo "Fútbol Callejero: da sua historicidade à potencialidade para o ser mais", de Belmonte e Souza Junior (2017).
} 
discentes para investigar os processos educativos que emergiram da prática social da mediação nas aulas de Educação Física Escolar; Souza Junior, Martins e Belmonte (2015) tratam da possibilidade de utilização da metodologia do Fútbol Callejero na Educação Física Escolar, explicitando os processos educativos na dimensão atitudinal dos saberes.

Os saberes atitudinais são relacionados à maneira com que os/as alunos/as se comportam no momento de execução das atividades propostas, demonstrando ser responsáveis, evidenciando atitudes de respeito, se são empáticos/as, solidarizam perante outrem e como agem perante o ato de incluir. Enquanto os saberes conceituais estão ligados aos conhecimentos teóricos dos conteúdos, como as regras e o histórico das práticas corporais, os saberes procedimentais ou corporais são referentes à prática, ou seja, à execução dos movimentos e a atividade física em si (GONZÁLEZ; BRACHT, 2012).

Há uma relação muito estreita entre os saberes atitudinais e os conhecimentos socioemocionais presentes na Base Nacional Comum Curricular (BNCC), documento que é uma referência para o estabelecimento das habilidades e competências que devem ser desenvolvidas na escola.

$\mathrm{Na} \mathrm{BNCC}$ temos as habilidades socioemocionais "[...] atitudes e valores para resolver demandas complexas da vida cotidiana, do pleno exercício da cidadania e do mundo do trabalho" (BRASIL, 2018, p. 8) como um processo que deve ser previamente planejado e trabalhado em todos os componentes curriculares, visto que "[...] a educação tem um compromisso com a formação e o desenvolvimento humano global, em suas dimensões intelectual, física, afetiva, social, ética, moral e simbólica" (BRASIL, 2018, p. 16).

A BNCC é um documento elaborado pelo Ministério da Educação (MEC) que serve de referência para as escolas e contém um conjunto de aprendizagens essenciais e indispensáveis que devem estar presentes nos currículos e propostas pedagógicas. "Essa referência é o ponto ao qual se quer chegar em cada etapa da Educação Básica, enquanto os currículos traçam o caminho até lá" (BRASIL, 2018, p. 5). Nesse sentido, o Currículo Paulista, que é alinhado à BNCC, enfatiza a necessidade de desenvolvimento de competências socioemocionais, colocando que a escola deve contribuir para o autoconhecimento, a construção identitária, as experiências em participação colaborativa, a crítica e para a produção de conhecimento (SÃO PAULO, 2019).

Para pensar e desenvolver meu Plano de Trabalho Anual utilizei a BNCC e o Currículo Paulista. Esses documentos evidenciam as Habilidades, Competências e Conteúdos que devem ser vivenciados em cada ano escolar frequentado pelos/as alunos/as. Assim, selecionei o tema "Esportes de Invasão", previsto para ser desenvolvido no $5^{\circ}$ ano do Ensino Fundamental, conforme a BNCC.

Após a escolha do tema, selecionei as atividades de ensino/aprendizagem que compuseram as aulas, elaborando um documento chamado Unidade Didática, ou seja, uma série ordenada e articulada de atividades (ZABALA, 1998), que contém a apresentação do tema, a observação das aulas, os debates gerados pelas investigações e vivências, e os exercícios que auxiliam a sistematização do estudo.

Pensando em proporcionar atividades que contribuíssem para o desenvolvimento e vivência da aprendizagem referente aos saberes atitudinais, sistematizei uma Unidade Didática que se apropriou da lógica dos Esportes de Invasão que foi combinada com a Metodologia Callejera, visando potencializar reflexões nos momentos de rodas de conversa ( $3^{\circ}$ Tempo).

Como no Fútbol Callejero tive muita dificuldade em lidar com os comportamentos competitivos, de exclusão e reprodução de comportamentos que 
verificamos nos espaços fora da escola, desenvolvi em minhas aulas o esporte de invasão ${ }^{5}$ Rúgbi touch (toque).

O Rúgbi touch é jogado por duas equipes que devem proteger as respectivas áreas de pontuação e invadir o campo adversário; o/a jogador/a de posse de uma bola oval marca o ponto quando consegue colocá-la no chão, depois de ultrapassar a linha demarcatória do fundo do campo adversário; se quem estiver segurando a bola for tocado, deve passar a mesma para outro/a jogador/a; se a bola cair no chão ou for lançada para frente, a sua posse mudará de time.

\section{Processo Metodológico}

A investigação foi realizada a partir de uma pesquisa-ação de abordagem qualitativa com observação, confecção e análise de diário de campo.

[...] a pesquisa-ação, argumenta Appolinário (2011, p.146) é uma modalidade de pesquisa cuja ênfase é "resolver, através da ação, algum problema coletivo no qual os pesquisadores e sujeitos da pesquisa estejam envolvidos de modo cooperativo e participativo". $\mathrm{Na}$ pesquisa-ação, os pesquisadores desempenham papel ativo na resolução dos problemas (DEL-MASSO; COTTA; SANTOS, 2020, p. 9).

Essa pesquisa foi realizada através das observações das aulas desenvolvidas, que posteriormente foram registradas compondo as notas de campo de um diário. Dentre os vários instrumentos possíveis de serem utilizados, o diário de campo (BOGDAN; BIKLEN, 1994) foi o instrumento que proporcionou o retorno às observações sobre os eventos ocorridos durante as atividades com o Rúgbi touch, resgatando os momentos vividos, permitindo refletir sobre eles.

A pesquisa foi desenvolvida em uma escola pública da rede Estadual de São Paulo, na cidade de São Carlos, localizada em um bairro periférico originado por um conjunto habitacional popular. Contribuíram para o desenvolvimento da pesquisa alunos/as do $5^{\circ}$ ano do Ensino Fundamental.

Os dados para análise foram coletados após inserção para participação e observação nas/das aulas em que foram ministradas, a partir da aplicação de uma Unidade Didática sobre Esportes de Invasão as quais auxiliaram a construção de 16 diários com as Notas de Campo.

O estudo passou por todas as etapas exigidas e somente teve início após a aprovação do Comitê de Ética em Pesquisa em Seres Humanos (CEP-UFSCar), constante no parecer n. 3.245.111.

Os dados foram analisados a partir de leituras atentas das informações contidas nos diários de campo produzidos após as intervenções, para que, ao voltar às observações, sejam identificadas situações que no momento da intervenção passaram despercebidas.

$\mathrm{Na}$ busca de fundamentação teórica que contribuísse para a coleta e análise das informações observadas em campo utilizei as etapas propostas por Jara-Holliday (2006), retomando o material escrito nas Notas de Campo e áudios das aulas, que compõe a fase

\footnotetext{
5 “Invasão ou territorial: conjunto de modalidades que se caracterizam por comparar a capacidade de uma equipe ao introduzir ou levar uma bola (ou outro objeto) a uma meta ou setor da quadra/campo defendida pelos adversários (gol, cesta, touchdown etc), protegendo, simultaneamente, o próprio alvo, meta ou setor do campo (basquetebol, frisbee, futebol, futsal, futebol americano, handebol, hóquei sobre grama, polo aquático, rúgbi etc.)" (SÃO PAULO, 2019, p. 260).
} 
"Recuperação do processo vivido", para "[...] o ordenamento e a classificação das informações, o que deve permitir reconstruir, de forma precisa, os diferentes aspectos da experiência" (JARA-HOLLIDAY, 2006, p. 87).

Através de leituras atentas das Notas de Campo identifiquei categorias de análise decorrentes das observações realizadas em aulas que convergiam para situações ou temas de momentos com troca de saberes e tomada de consciência por parte de todos(as) envolvidos(as). As denominações das categorias foram inspiradas em falas das crianças que geraram discussões nos momentos que ocorreram, de modo que contribuíram para o trabalho com os saberes atitudinais.

\footnotetext{
Chegamos aqui ao "tempo" chave do processo de sistematização: a interpretação crítica do processo vivido. Todos os outros momentos estão em função deste [...]. Trata-se, agora, de ir mais além que o descritivo, de realizar um processo ordenado de abstração, para encontrar a razão de ser do que aconteceu no processo da experiência. Por isso, a pergunta chave desse "tempo" é: Porque aconteceu o que aconteceu? (JARA-HOLLIDAY, 2006, p. $88)$.
}

Nesse momento chamado de "Reflexão de fundo: porque aconteceu o que aconteceu" realizei reflexões sobre os acontecimentos que foram observados, pois é necessário transcender a mera descrição para desvelar os sentidos e os significados dos eventos registrados nos diários de campo.

\section{RESUlTAdOS}

Apresento as reflexões e emersões geradas pelos ocorridos nas intervenções, separadas nas categorias "Mas ele ééé boooom!" e "As meninas ficam fazendo unha!", que surgiram da análise dos dados das observações.

\section{MAS ELE ÉÉÉ BOOOOM!}

Essa categoria tem origem em um fato ocorrido em aula na qual eu usava uma camiseta de um time de basquete norte-americano chamado Golden State Warriors.

\footnotetext{
Após ver a camiseta, Munlock perguntou se eu gostava do Curry. Curry é o sobrenome de um jogador estrela do time. Demorei para responder, pois pensava em uma maneira de falar que não gostava do jogador por conta de achar que não possui um comportamento educado frente aos jogadores dos outros times. Após responder que não gostava, ouvi de Munlock:

- Purquê professor?

Fabio: - Acho que ele é muito estrelinha, acho que isso não é legal.

Munlock: - Mas ele ééé boooom!!!!!

- Sim, mas eu não concordo com algumas atitudes dele enquanto pessoa, enquanto jogador. Respondi (Diário X, 13/08/2019).
}

Como descrito no trecho do diário, Curry é reconhecido para além dos limites do território estadunidense, realmente é um jogador com muitas habilidades de valor incontestável, porém isso não o exime de ser respeitoso não só com os jogadores de sua equipe, torcida, como também com integrantes dos times adversários. Ademais, enquanto pessoa pública seria prudente que tivesse um comportamento ímpar visto que muitos/as o tem como exemplo a ser seguido.

Essa categoria é reflexo das preocupações que possuímos com o rendimento, a performance e a competição que somos incentivados a ter e que é evidenciada em 
nossas falas e atitudes nas várias interações que temos no mundo, como na produção e execução do trabalho, visto que:

A todo o momento somos distribuídos, sem o direito pessoal a escolhas, dentro de sistemas de classificação de mulheres e de homens avaliados segundo critérios utilitários de competência/competitividade. Pessoas colocadas entre escalas numéricas de comparação apressada que nos dividem entre os poucos da "ponta" e os outros todos do "resto" (BRANDÃO, 2005, p. 89).

Em vários momentos do jogo temos situações que podem ser relacionadas à competição. Os processos educativos surgem no sentido de pensar sobre a importância dada à competição e sobre o entendimento da dinâmica da Metodologia Callejera, na qual o resultado do placar no $2^{\circ}$ Tempo da atividade não é determinante para indicar o time vencedor.

\begin{abstract}
Chocolate veio até mim para perguntar sobre o placar, para mim ele sabia que seu time vencia apertado, o placar mantinha-se em $4 \times 3$, eu perguntei para ele se isso era importante, e quanto valeria esse resultado ao final do jogo, essa valorização à competição e à vitória me incomoda, porém vejo que com essas questões que lancei a ele não será possível desenvolver uma reflexão mais profunda sobre esse ponto. Ele voltou na brincadeira e logo veio Jack2 falando, "Mais um professor", me informando que havia pontuado, 5x3 (Diário V, 11/06/2019).
\end{abstract}

Um desconforto foi causado em mim por conta de entender que, na fala do aluno, ocorria a valorização do resultado da partida em detrimento da realização da atividade, da diversão e do encontro ocorrido por conta do jogo. No instante do acontecimento tivemos uma rápida conversa na qual propus uma questão para que esse estudante refletisse sobre a importância em vencer, tendo em vista que a realização de um placar ampliado no jogo não levaria muito benefício para a contagem final. Brandão (2005) faz uma reflexão nesse sentido:

E é bem verdade que [...] é bem melhor um "três a um" do que um "dois a dois". No jogo, a regra universal é que dois (duas pessoas, dois times, duas equipes) [...] entram nele em condições supostamente iguais, [...]. Todos estão submetidos da mesma maneira às mesmas regras. $E$ então um vence $o$ outro porque foi: mais capaz, mais hábil, mais forte, mais inteligente, mais astuto, mais sagaz, mais bem treinado, "mais" [...]. Essa é a "regra do jogo". E por isso se joga (BRANDÃO, 2005, p. 87).

Só se joga para vencer, senão qual seria o objetivo de participar de uma partida? O aluno Chocolate pode ter sentido, em algum momento, que seu time corria algum risco de perder, visto que está incorporado que o importante, ou o jogo só é válido para quem vence, perder torna-se uma vergonha, portanto, válido é evidenciar as suas capacidades e habilidades superiores aos/às outros/as com o objetivo de diminuir a sensação de derrota, justificando não ser culpado por uma eventual perda do time.

Outro trecho traz a preocupação, principalmente dos meninos, em formar uma equipe competitiva com possibilidades de vencer qualquer adversário. Deparamos com o desejo da formação do "Dream team" (Time dos sonhos) por parte de alguns alunos:

Marcos e Munlock são amigos e ambos são habilidosos, como os times foram separados de maneira que não reunissem várias pessoas habilidosas na mesma equipe em vários momentos alunos e alunas pedem para mudar de 
time, pois temos incorporado que o importante é vencer. Como já relatei em outro diário, Munlock é bastante competitivo e se irrita em vários momentos do jogo quando alguém do seu time erra, ou quando sofrem ponto (Diário VIII, 06/08/2019).

Novamente, em outra aula (Diário IX, 08/08/2019), surgiu a possibilidade de passar alguns integrantes de um time para outro, de modo que ficassem com número equivalente de membros. Na primeira fala, Marcos expõe que seu time precisa apenas de um jogador para que seu time possa jogar de maneira supostamente equilibrada. $\mathrm{Na}$ sequência das falas, Goege externaliza seu desejo de formação de um time competitivo colocando que deveriam escolher alguém do outro time.

Ao que fui questionado por E-Manoela, nesse sentido, pensando na Metodologia Callejera, principalmente em relação aos protagonismos dos/as integrantes, não resolvi o problema eu mesmo, dirigi a questão para toda gente de modo a verificar se alguém do time que possuía mais integrantes poderia passar para o outro. Enquanto os meninos disseram não, as meninas disseram sim. Identifiquei esses acontecimentos como sendo dissonantes, ou seja, divergentes em relação a essa categoria, pois as meninas não se importaram em compartilhar membros de seu grupo para que o jogo ocorresse, enquanto os meninos queriam escolher quem deveria ir para o outro, de modo que não se sentissem prejudicados.

Em outros momentos ocorreram situações que estão relacionadas com o desejo de vencer, ou fazer parte de um grupo vencedor:

Logo na primeira parada Amanda veio pedir para mudar para o time de Munlock novamente, eu disse para ela experimentar, jogar e se não desse certo nós pensaríamos em mudar, porém se ela mudasse outrem também poderia mudar e isso levaria um bom tempo da aula para resolver (Diário IV, 06/06/2019).

O entendimento que tive foi que Amanda desejava mudar de time, pois julgando que a equipe que ela pertencia não era competitiva suficientemente. No outro time haveria uma maior chance dela vencer, visto que Munlock é considerado um garoto com habilidades motoras acima da média dos/as outros/as jogadores/as, tendo condições de levar a equipe à vitória.

Brandão (2005, p. 88) nos ajuda a pensar sobre a nossa repulsa em aceitar os momentos em que perdemos, seja a disputa que for, como vivemos imersos:

[...] na economia capitalista, em que se proclama - inclusive em alguns modelos de formação de crianças e de jovens através da educação - que todos podem 'vencer na vida' e que isto depende apenas da 'vontade de cada um', o que de verdade acontece é o exato oposto.

Em "diferentes setores da vida de todos", nas interações que temos no trabalho, com a família ou em momentos de lazer; em toda e qualquer atividade diária, é urgente perceber ' $[\ldots . .$.$] como cada vez mais a ilusória 'vitória' de alguns poucos custa o preço da$ derrota, da exclusão, da infelicidade de muitos" (BRANDÃ̃, 2005, p. 88). Continua o autor explicando, que não só para um vencer outros precisam perder, mas que os estímulos dados às crianças nesse sentido acabam gerando a competição, o individualismo, a falta de empatia, a ansiedade e um desconforto emocional desde as vivências escolares. 
Entretanto, tais situações que ocorreram nas vivências são formas geradoras de discussões que contribuíram com a troca de ideias para uma conscientização das ações que foram tomadas e as consequências por elas geradas.

Gabiela começou a falar que notou o movimento de Munlock no jogo que trocava seus passes com Brena, eu disse que havia notado esse movimento e que era uma estratégia de jogo adotada por ele visando satisfazer a regra de que meninos deveriam passar a bola para meninas e vice-versa, logo, inseri a questão do Companheirismo na discussão perguntando para Leo se ele tinha ficado satisfeito com o número de vezes que havia recebido a bola durante o jogo (Diário XVI, 12/09/2019).

Nesse momento de mediação tentei despertar em todos/as o pensamento em relação a atitudes de companheirismo e compartilhamento diante da competição. $\mathrm{O}$ intuito daquele momento em ouvirmos a fala de Leo foi de que os/as alunos/as sentissem empatia pelo sujeito do ocorrido e quem sabe, percebessem em outros momentos pessoas à parte de outras atividades e assumissem uma postura de inclusão.

\section{AS MENINAS FICAM FAZENDO UNHA!}

Nessa categoria estão questões relacionadas ao gênero e aos estereótipos do comportamento masculino e feminino, em que os homens são fortes, devem dominar, tomar decisões, enquanto as mulheres são frágeis, atenciosas, simpáticas, submissas, cuidadoras, recatadas (BELMONTE; GONÇALVES JUNIOR; SOUZA JUNIOR, 2014).

O nome dessa categoria surgiu no $1^{\circ}$ Tempo de uma aula em que eu instigava os/as alunos/as a pensar meios de incluir as meninas a participarem ativamente em mais lances do jogo e uma das ideias sugeridas foi a de que os pontos das meninas deveriam valer três vezes mais que os dos meninos. Um garoto justificou a validade dos pontos relacionando ao fato de algumas meninas utilizarem esmalte para pintar as unhas.

Perguntei ... por quê os pontos das meninas deveriam valer mais. Muitos(as) falavam ao mesmo tempo, e a fala de Goege me chamou a atenção:

- As meninas ficam fazendo unha.

- As meninas também jogam Vôlei, jogam Futebol. Retrucou Brena.

- Meninas também praticam esportes. Sabrina falou juntamente com Brena. (Diário XII, 29/08/2019).

As discussões ocorreram em vários sentidos, crianças verbalizavam suas visões estereotipadas e outras rebatiam, fazendo a defesa das maneiras de vida das meninas no sentido de esclarecimento das ideias sobre esse tipo de entendimento machista ${ }^{6}$ sobre as mulheres que podem ser verificadas em outras situações de aula.

As origens sociais do machismo são longínquas, ocasionando a incorporação pelas pessoas de que as mulheres não devem praticar atividades físicas. Quando algum tipo de exercício é permitido, este deve servir para acentuar um "modelo" de corpo idealizado por uma sociedade patriarcal. As atividades físicas que podem modificar os corpos femininos contribuindo para formação de linhas arredondadas são desejadas, enquanto os exercícios que promovem o aumento aparente da musculatura, deixando o corpo com linhas mais retas, tirando o aspecto frágil, são mal vistos e devem ser evitados (BONFIM; MORAES, 2016).

\footnotetext{
6 "O machismo é o preconceito que exerce uma função social de dominação dos homens sobre as mulheres, inferiorizando-as com a finalidade de controlar comportamentos e subjugar sua existência [...]" (CFSS, 2019, p. 7).
} 
Fabio de Moraes; Yara Aparecida Couto

De acordo com Gregory (2014):

As consequências das concepções machistas e sexistas são sentidas pelas mulheres em seu dia a dia, desde crianças, quando, a princípio, seu mundo ainda estaria livre de convenções. Considera-se natural que meninos brinquem com bola e meninas com bonecas, que enquanto os meninos saem para as atividades esportivas no contra turno escolar, como o Programa $2^{\circ}$ Tempo, do Ministério do Esporte, as meninas tenham que ficar em casa, cuidando dos irmãos menores (p. 11).

Mesmo após os depoimentos evidenciando a atuação das garotas em diferentes atividades esportivas: "As meninas também jogam Vôlei, jogam Futebol” e "Meninas também praticam esportes" (Diário XII, 29/08/2019), dois meninos responderam: “[...] que elas não gostavam" e "As meninas são delicadas, os homens são cabra-macho" (Diário XII, 29/08/2019).

As meninas, atentas, rebatiam os discursos um-a-um na medida em que ocorriam e a partir das falas e visões estereotipadas demonstradas por alguns meninos, busquei despertar pensamentos sobre o fato das meninas terem menos possibilidades de vivências em atividades físicas.

Enquanto educador, eu observava os movimentos dos meninos e meninas durante o jogo e procurava incentivar o diálogo tanto no $3^{\circ}$ Tempo quanto no $1^{\circ}$. Baseado nos ocorridos da aula anterior, procurava estimular a proposição de regras no $1^{\circ}$ Tempo de jogo. Esse posicionamento tinha a intenção de promover a inclusão de regras para aumentar a participação feminina no jogo.

Algumas regras criadas foram: a atribuição maior no valor dos pontos realizados pelas jogadoras; a bola deveria passar por mais de três pessoas no time antes que finalizassem a jogada; meninos deveriam passar a bola para as meninas. Julgo que essas medidas, além de causar motivação nos/as participantes, buscaram incentivar atitudes de inclusão de pessoas que ficavam à margem da atividade.

A ocorrência, em várias intervenções, de regras para a inclusão de mais jogadores/as foi surtindo efeito, aumentando o número das meninas na participação da atividade.

Noto que algumas meninas começam a tentar atacar, fato que não havia ocorrido na brincadeira do dia anterior. Após ter saído da aula anterior, já incomodado com a pouca participação das meninas em relação às ações de ataque, fiquei pensando se deveria fazer alguma regra que motivasse uma maior participação das meninas em outras partes do jogo, não somente colaborando com a defesa de seus times (Diário V, 11/06/2019).

Em outra ocasião, algumas meninas se arriscaram mais e na conversa ao final da aula pude notar mais alegria e contentamento na realização dos feitos. Discutir questões sobre gênero foi colocado como um dos objetivos da aula 3 , porém preciso retomar essa discussão no sentido de contribuir para que meninos e meninas despertem para as questões de igualdade (Diário V, 11/06/2019).

No decorrer das aulas, ia reforçando as reflexões transcorridas em outros dias e momentos, no sentido de ir instigando a classe a pensar sobre a participação das meninas no jogo.

Coloquei questões mais diretas sobre a participação delas no jogo e percebi através da fala das garotas que havia medo de ser repreendidas por errarem, porque não imaginavam que pudessem atacar também, porque os meninos 
haviam dito que elas deveriam ficar ali, e porque não haviam visto nenhuma menina indo atacar (Diário V, 11/06/2019).

Com os diálogos estabelecidos naquele momento notei que os motivos são vários, como: as meninas se anulam preferindo não participar do jogo por receio em errar e assim serem repreendidas pelos meninos; alguns meninos haviam sugerido que assumissem determinado posicionamento em quadra, posicionamentos esses que não oportunizavam ações ofensivas.

Apesar do aumento da participação feminina no jogo, ainda estava presente a falta de cooperação/companheirismo:

\begin{abstract}
Marcos, que era de outro time disse que quando eles estavam jogando algumas pessoas discutiam sobre quem deveria atacar, e que eram só os meninos que queriam passar para o campo de ataque. Então voltei a perguntar se alguma menina queria passar para atacar, mas os meninos falaram para não passar. Priscila disse que queria passar, mas não deixaram, mas que Emanuela tinha atacado, os meninos se defendiam dizendo que não tinham falado nada (Diário V, 11/06/2019).
\end{abstract}

Nesse trecho percebem-se os papeis sociais atribuídos: os meninos devem ir ao ataque, ficam expostos aos perigos de invadir o território adversário, enquanto as meninas ficam com a responsabilidade de proteger, cuidar do campo de defesa, evitando a invasão do time adversário.

Passadas mais algumas discussões, ainda tivemos que continuar propondo interrogações que suscitassem as crianças a perceberem suas atitudes de exclusão e caminharem rumo ao companheirismo: "Allan disse que as meninas não corriam o mesmo que os meninos. Várias meninas reclamaram fortemente e Allan logo reelaborou sua fala dizendo que as meninas corriam mais ou menos" (Diário XII, 29/08/2019).

\title{
CONSIDERAÇÕES FINAIS
}

Foi possível perceber que os processos educativos e, consequentemente, a troca de saberes, ocorreram em vários momentos das intervenções, contribuindo em diálogos que levassem para atitudes de compartir em detrimento de competir, como no reconhecimento de situações relacionadas a gênero em que as meninas sofriam diversos preconceitos e exclusões.

$\mathrm{Na}$ categoria "Mas ele ééé boooom!" ficaram evidenciadas a promoção do rendimento, a competição e a valorização da vitória. As trocas de saberes foram em sentido de percebermos nossa ânsia pelo alto rendimento, mas também a importância da promoção da cooperação e da conscientização de que o sentido jogo não deve ser a busca pela vitória.

$\mathrm{Na}$ categoria "As meninas ficam fazendo unha!" foram percebidas questões referentes ao machismo, ao poder associado ao homem. Os diálogos e trocas de saberes foram potencializados nos $1^{\circ} \mathrm{s}$ e $3^{\circ} \mathrm{s}$ Tempos de jogo, através da fala das meninas. Foi possível notar um posicionamento maior e de mais garotas, tanto em relação à exposição de ideias quanto à participação nas atividades. Também houve contribuição em relação à ampliação da visão de todos/as sobre a preferência na realização de práticas corporais e utilização de produtos de beleza.

Percebi que o encontro do Fútbol Callejero e da Metodologia Callejera com a escola foi muito proveitoso, pois, apesar das dificuldades, as aulas ministradas puderam 
proporcionar momentos de despertar a solidariedade e a cooperação, nos levando à abertura de horizontes. Foi como "abrir a cancha".

\begin{abstract}
"Abrir a cancha" é a frase que se utiliza em Defensores para expressar a possibilidade de avançar em uma direção nova, para expressar que é preciso dar espaço a outros para que incorpore e se somem ao progresso da organização (ARTAVIA-LORÍA, 2008, p. 13).
\end{abstract}

\title{
REFERÊNCIAS
}

ARTAVIA-LORÍA, R. Defensores del Chaco: o futuro construído por todos. Santiago: Viva Trust, 2008.

BELMONTE, M. M.; GONÇALVES JUNIOR, L.; SOUZA JÚNIOR; O. M. de. Fútbol callejero e educação das relações de gênero. In: SALDANHA, D. F.; GONZALEZ, R. H. (orgs.). Projetos sociais para crianças e adolescentes. Juiz de Fora: Editora Garcia, 2018. p. 251-274.

BELMONTE, M. M; SOUZA JUNIOR, O. M. Fútbol callejero: da sua historicidade à potencialidade para o ser mais. In: COLÓQUIO DE PESQUISA QUALITATIVA EM MOTRICIDADE HUMANA: ECOMOTRICIDADE E BEM VIVER, 7., 2017, Aracaju; São Cristóvão. Anais [...]. São Carlos: SPQMH, 2017. p. 553-559.

BODGAN, R; BIKLEN, S. Notas de campo. In: BODGAN, R; BIKLEN, S. Investigação qualitativa em educação: uma introdução à teoria e aos métodos. Porto: Porto Editora, 1994. p.150-175.

BONFIM, A; MORAES, C. Mulher no futebol: no campo e nas arquibancadas. In: STEFANO, D; MENDONÇA, L. (orgs.). Direitos humanos no Brasil 2016: relatório da Rede Social de Justiça e Direitos Humanos. São Paulo: Editora Outras Expressões, 2016. p. 177-187.

BRANDÃO, C. R. Jogar para competir ou jogar para compartir? Da competição contra o outro a cooperação com o outro. In: BRANDÃO, C. R. Aprender o amor: sobre um afeto que se aprende a viver. Campinas: Papirus, 2005. p. 85-116.

BRASIL. Ministério da Educação. Educação Física. In: Base Nacional Comum Curricular: educação é a base. Brasília: MEC/CONSED/UNDIME. 2018. Disponível em: http://basenacionalcomum.mec.gov.br/wp-content/uploads/2018/02/bncc-20dez-site.pdf. Acesso em: 10 maio de 2019.

CASTRO, L. E. A construção de valores orientada pela metodologia callejera na educação física escolar. 2018. Dissertação (Mestrado em Docência para a Educação Básica) - Faculdade de Ciências, Universidade Estadual Paulista Júlio de Mesquita Filho, Bauru, 2018.

CFSS. Conselho Federal de Serviço Social. Machismo. Brasília: CFSS, 2019. (Série Assistente Social no combate ao preconceito, Caderno 6). Disponível em: http://www.cfess.org.br/arquivos/CFESSCaderno06-Machismo-Site.pdf. Acesso em: 10 maio 2019.

DEL-MASSO, M. C. S; COTTA, M. A. C; SANTOS, M. A. P. Ética em pesquisa científica: conceitos e finalidades. São Paulo: Núcleo de Educação a Distância da Unesp; Programa Rede São Paulo de Formação Docente (Redefor II), 2014. (Texto 2 da disciplina 4 do curso Especialização em Educação Especial na Perspectiva da Educação Inclusiva). Disponível em: https://goo.gl/W2HX7b. Acesso em: 24 nov. 2018.

GONÇALVES JUNIOR, L; LEMOS, F. R. M; MORAES, F; VAROTTO, N. R. "Fútbol Callejero" na Educação Física Escolar: processos educativos emergentes de uma intervenção. Revista Brasileira de Iniciação Científica, Itapetininga, v. 5, n. 5, p. 104-120, out.-dez. 2018.

GONZALEZ, F. J; BRACHT, V. Metodologia do ensino dos esportes coletivos. Vitória: UFES, 2012. 
GREGORY, B. H. M. Esporte e lazer: direitos de meninas e mulheres de todas as idades. Revista do Observatório Brasil da Igualdade de Gênero, v. 4, n. 6, p. 11-14, 2014.

JARA-HOLLIDAY, O. Para sistematizar experiências. 2. ed. Brasília: MMA, 2006.

MORAES, F. Educação física escolar e a contribuição da metodologia callejera nos conhecimentos atitudinais. 2020. Dissertação (Mestrado Profissional em Educação Física), Universidade Federal de São Carlos, São Carlos, 2020.

OLIVEIRA, M. W.; SILVA, P. B. G.; GONÇALVES JUNIOR, L.; MONTRONE, A. V. G.; JOLY, I. Z. L. Processos educativos em práticas sociais: reflexões teóricas e metodológicas sobre pesquisa educacional em espaços sociais. In: OLIVEIRA, M. W.; SOUSA, F. R. (org.). Processos educativos em práticas sociais: pesquisa em educação. São Carlos: EdUFSCar, 2014. p. 29-46.

ROSSINI, L.; SERRANI, E.; WEIBEL, M.; WAINFELD, M. Fútbol callejero: juventud, liderazgo y participación - trayectorias juveniles en organizaciones sociales de América Latina. Buenos Aires: FUDE, 2012.

SÁNCHEZ, L; SALERMO, J. El Fútbol Callejero, un deporte inclusive en Chos Malal, Provincia del Nelquén. EFDeportes.com, Buenos Aires, v. 17, n. 175, p. 1-7, 2012.

SÃO PAULO (Estado). Secretaria da Educação. Educação física. In: SÃO PAULO (Estado). Secretaria da Educação. Currículo Paulista. São Paulo: SEE, 2019. p. 247-279.

SOUZA JUNIOR, O. M; MARTINS, M. Z; BELMONTE, M. M. Fútbol Callejero e Educação Física Escolar: a explicação dos saberes atitudinais pelo jogo em três tempos. In: CONGRESSO INTERNACIONAL DE PEDAGOGIA DO ESPORTE, 6., 2015, Maringá. Anais [...]. Maringá: UEM, 2015. p. 1-6.

ZABALA, A. As sequências didáticas e as sequências de conteúdo. In: ZABALA, A. A prática educativa: como ensinar. Porto Alegre: ArtMed, 1998. p. 53-87.

Recebido em: 03 jan. 2021.

Aprovado em: 18 abr. 2021. 